University of Wollongong

Research Online

Faculty of Engineering and Information

Faculty of Engineering and Information

Sciences - Papers: Part A

Sciences

$1-1-2015$

\title{
Block shear failure planes of bolted connections - direct experimental verifications
}

\section{Lip H. Teh}

University of Wollongong, Iteh@uow.edu.au

Mehmet E. Uz

University of Wollongong, meuz@uow.edu.au

Follow this and additional works at: https://ro.uow.edu.au/eispapers

Part of the Engineering Commons, and the Science and Technology Studies Commons

Research Online is the open access institutional repository for the University of Wollongong. For further information contact the UOW Library: research-pubs@uow.edu.au 


\title{
Block shear failure planes of bolted connections - direct experimental verifications
}

\author{
Abstract \\ This paper presents direct experimental verifications of the active shear planes in bolted connections, \\ previously identified by the first author for determining the block shear capacity. The laboratory test \\ results were obtained by independent researchers for specimens where the applied loads were resisted \\ by the "block" in shear only. The first set consists of five bolted connection specimens in the webs of wide \\ flange sections where the tensile resistance planes had been sawn off. The second set consists of ten \\ bolted connection specimens each in one leg of an angle section that had fractured completely along the \\ net tensile plane through a block shear failure. Comparisons among the gross, net, and active shear \\ planes against the independent laboratory test results showed that the critical shear planes of bolted \\ connections were best represented by the active shear planes rather than either the gross or the net shear \\ planes. It is also pointed out that full or almost full shear strain hardening was generally achieved at the \\ ultimate limit state of block shear failure of bolted connections in hot-rolled steel plates or sections, \\ irrespective of the connection length. Verification against independent laboratory test results of tee \\ sections bolted at the web reinforces this point.

\section{Disciplines} \\ Engineering | Science and Technology Studies

\section{Publication Details} \\ Teh, L. H. \& Uz, M. E. (2015). Block shear failure planes of bolted connections - direct experimental \\ verifications. Journal of Constructional Steel Research, 111 70-74.
}




\title{
Block Shear Failure Planes of Bolted Connections - Direct Experimental Verifications
}

\author{
Lip H. Teh ${ }^{*}$, Mehmet E. Uz \\ School of Civil, Mining \& Environmental Engineering, University of Wollongong, Wollongong, NSW 2522, \\ Australia. \\ ${ }^{*}$ Corresponding author at School of Civil, Mining \& Environmental Engineering, University of Wollongong, \\ Wollongong, NSW 2522, Australia. Tel: +61242213564, fax: +61242213238, e-mail: lteh@uow.edu.au
}

\begin{abstract}
This paper presents direct experimental verifications of the active shear planes in bolted connections, previously identified by the first author for determining the block shear capacity. The laboratory test results were obtained by independent researchers for specimens where the applied loads were resisted by the "block" in shear only. The first set consists of five bolted connection specimens in the webs of wide flange sections where the tensile resistance planes had been sawn off. The second set consists of ten bolted connection specimens each in one leg of an angle section that had fractured completely along the net tensile plane through a block shear failure. Comparisons among the gross, net and active shear planes against the independent laboratory test results showed that the critical shear planes of bolted connections were best represented by the active shear planes rather than either the gross or the net shear planes. It is also pointed out that full or almost full shear strain hardening was generally achieved at the ultimate limit state of block shear failure of bolted connections in hot-rolled steel plates or sections, irrespective of the connection length. Verification against independent laboratory test results of tee sections bolted at the web reinforces this point.
\end{abstract}




\section{Introduction}

Teh \& Clements [1] have described how the design provisions against block shear failures of bolted connections [2-7] oscillated over the years since its discovery in 1978 by Birkemoe \& Gilmore [8], as summarised in Table 1. The most important factor causing the uncertainty was the use of the gross and the net areas in computing the yielding and the rupture resistance terms, respectively. The gross shear area, annotated in Figure 1(a) as $A_{\mathrm{gv}}$, is used when the failure mechanism is shear yielding and tensile rupture $[3,5,7]$, while the net shear area, annotated in Figure 1(b) as $A_{\mathrm{nv}}$, is used for the shear rupture and tensile yielding mechanism [3,6] or simultaneous shear and tensile rupture mechanism [2, 4, 7]. The inconsistent definitions for the failure planes gave rise to unnecessary anomalies that led to repeated amendments to the design provision.

In a recent paper, Clements \& Teh [9] have argued that, whether it is shear yielding or shear rupture, the critical shear planes lie midway between the gross and the net shear planes, as indicated by the results of nonlinear contact finite element analysis. These shear planes, depicted in Figure 2 and denoted $A_{\mathrm{av}}$, are termed the active shear planes [1,9] to distinguish them from the gross and net shear planes. In Figure 2, the variable $n_{\mathrm{r}}$ is the number of bolt rows, $d_{\mathrm{h}}$ is the bolt hole diameter, and $t$ is the plate thickness.

Although the finite element analysis results of Clements \& Teh [9] clearly showed the location of the active shear planes, there has been no direct experimental verification supporting the use of the active shear planes. Comparisons among the gross, net and active shear planes against laboratory test results were carried out in the context of block shear failures that invariably involved both tensile and shear resistance components [1,9]. A more convincing case will result 
if the comparisons are made against laboratory test specimens each of whose ultimate load depends on the shear resistance only. In addition, verifications against independent laboratory test results obtained by different researchers are desirable.

In this paper, comparisons among the gross, net and active shear planes will be made against independent laboratory test results where only the shear resistance is relevant. Five of the specimens are bolted connections in the webs of wide flange sections where the tensile resistance planes had been sawn off so that the applied loads were resisted by shear only [10], as illustrated in Figure 3(a). The other ten specimens are bolted connections each in one leg of an angle section that had fractured completely along the net tensile plane through a block shear failure [11], as illustrated in Figure 3(b). As the stroke displacement was continued following the tensile fracture, the applied load was resisted by shear only.

This paper also includes discussions on strain hardening during shear yielding leading to the block shear failure of a bolted connection, and verification of the proposed block shear equation against tee sections bolted at the web. Although the block shear failure mode was discovered thirty five years ago [8], there is continuing research in this area as represented by very recent papers [12-15].

\section{Shear resistance equations}

The net shear area $A_{\mathrm{nv}}$ depicted in Figure 1(b) has always been used in the North American specifications $[2-7,16]$ for determining the shear rupture resistance,

$$
P_{v}=0.6 F_{u} A_{n v}
$$


although it is also used in the Eurocode [17] for determining the shear yield resistance, where the tensile strength $F_{\mathrm{u}}$ is replaced with the yield stress $F_{\mathrm{y}}$. In any case, Clements \& Teh [9] have pointed out that the approach of using the net shear area $A_{\mathrm{nv}}$ ignores the fact that the planes coinciding with the centrelines of the bolt holes in the direction of loading do not have maximum shear stresses due to the bolt bearing condition.

Gross et al. [11] suggested that, based on their laboratory test results involving bolted connections that had fractured completely along the net tensile planes and were subjected to continued loading, the critical shear area was the gross shear area $A_{\mathrm{gv}}$ depicted in Figure 1(a). When the net shear area $A_{\mathrm{nv}}$ was used for computing the shear rupture resistance, the average shear coefficient was found to be 0.71, significantly higher than the accepted value of 0.6. Therefore, according to Gross et al. [11], the shear rupture resistance would be computed from

$$
P_{v}=0.6 F_{u} A_{g v}
$$

However, Gross et al. [11] did not verify their suggestion against their laboratory test results. Equation (2) is therefore verified in the next section of this paper.

The finite element analysis results of Clements \& Teh [9] have indicated that the shear rupture resistance should be computed from the active shear area $A_{\mathrm{av}}$ depicted in Figure 2,

$$
P_{v}=0.6 F_{u} A_{a v}
$$




\section{Verification of active shear planes against laboratory test results}

Orbison et al. [10] sawed off the net tensile plane of their bolted webs, as illustrated in Figure 3(a), so that the applied load of each bolted connection specimen was resisted in the web by shear only. The ultimate test load is denoted $P_{\mathrm{t}}$ in the present work. All specimens were composed of A36 steel W12×14 sections, which had a nominal web thickness $t$ of $5.26 \mathrm{~mm}$. The A490 bolts used in the laboratory tests had a nominal diameter of $19 \mathrm{~mm}$, with a bolt hole diameter of $20.6 \mathrm{~mm}$ as indicated in Figure 3(a). The bolt spacing in the loading direction was invariably $63.5 \mathrm{~mm}$. The only relevant (nominal) geometry variables for their specimens were the number of bolt rows $n_{\mathrm{r}}$ and the end distance $e$, which are given in Table 2 for each specimen.

It can be seen from the ratios of ultimate test load to predicted shear resistance $P_{t} / P_{v}$, termed the professional factor in the literature [10, 11, 19], in Table 2, that Equation (3), which is based on the active shear planes, provides the most accurate estimates for the shear resistance. For every specimen, the professional factor of Equation (3) is considerably closer to unity compared to the other two equations, which make use of the net and gross shear areas respectively.

Gross et al. [11] continued the stroke displacement after an angle specimen bolted at one leg had failed in block shear, and the net tensile plane had fractured completely. In such a case, the applied load was resisted by the "block" in shear only, as illustrated in Figure 3(b). Ten A588 Grade 50 and three A36 steel angle braces, all with a nominal thickness of $6.35 \mathrm{~mm}$, were tested in this manner. However, three of the A588 specimens failed in a different mode and their results were not included. The nominal bolt hole diameter and bolt pitch were the same as those used by Orbison et al. [10], being $20.6 \mathrm{~mm}$ and $63.5 \mathrm{~mm}$, respectively. However, unlike the wide flange 
specimens [10], the end distance was constant at $38.1 \mathrm{~mm}$. The only (nominal) geometry variable was the number of bolt rows $n_{\mathrm{r}}$.

Since Equations (1) through (3) only make use of the tensile strength $F_{\mathrm{u}}$, the yield stress $F_{\mathrm{y}}$ of a specimen does not affect the calculations shown in Table 3. However, the ratios of tensile strength to yield stress $F_{\mathrm{u}} / F_{\mathrm{y}}$ are included in the table to provide insights into the extent of shear strain hardening along the active shear planes at the ultimate limit state of block shear failure (just before the net tensile section ruptured), as discussed in the next section.

As for the sawn-off wide flange specimens tested by Orbison et al. [10], it can be seen from the professional factors $P_{\mathrm{t}} / P_{\mathrm{v}}$ in Table 3 that Equation (3) also provides the most accurate estimates for the shear resistance of the fractured angle specimens tested by Gross et al. [11]. The resulting mean professional factor of 0.99 , which was computed by neglecting an outlier specimen (A5887), is considerably closer to unity compared to the other two equations. In fact, the mean professional factors $P_{\mathrm{t}} / P_{\mathrm{v}}$ of all three equations for the angle specimens shown in Table 3 are quite similar to those for the wide flange specimens shown in Table 2. For both sets of specimens, the average underestimation and overestimation caused by the use of the net and gross shear areas, respectively, are close to $20 \%$.

While it could be argued that Equation (3) might be over-optimistic when there were four bolt rows in the outlier specimen (A588-7), Teh \& Yazici [14] have demonstrated that the shear resistance term expressed by the equation, in conjunction with the tensile resistance term that assumed fully developed stresses (i.e. $F_{\mathrm{u}} A_{\mathrm{nt}}$ ), was accurate for determining the block shear capacities of such connections, including a high-strength steel specimen tested by Aalberg \& Larsen [18]. Furthermore, each of the wide flange specimens shown in Table 2 had at least four 
bolt rows. If the result of specimen A588-7 is included, then the mean professional factors $P_{\mathrm{t}} / P_{\mathrm{v}}$ of Equations (1), (2) and (3) will be 1.18, 0.78 and 0.97. The conclusion therefore remains the same.

The largest underestimation of the shear capacity by the use of the net shear area $A_{\mathrm{nv}}$ is $25 \%$ (for specimen No. 14, A588-6), and the largest overestimation by the use of the gross shear area $A_{\mathrm{gv}}$ is $32 \%$ (i.e. $1 / 0.76=1.32$ ), for specimens Nos. 2, 8, 9, and 12 .

Following the reviewers' comments, a clarification regarding the professional factors of Equation (3) which are shown to be less than unity in Tables 2 and 3 is provided here. These values do not indicate that Equation (3) is unconservative. The professional factors were calculated using the tensile strengths $F_{\mathrm{u}}$ obtained from the relevant tension coupons, shown in Tables 2 and 3, but it could be expected that some random specimens in the experimental batch had actual tensile strengths that were lower than that of the relevant tension coupon by an order of $5 \%$ or so. Small errors in dimensional measurements are also quite possible. What matters is that the mean professional factor should be close to unity, with a reasonably low coefficient of variation. The variability of material tensile strength and other parameters are accounted for in the design provision through a resistance factor [14], which ensures that the design equation achieves or exceeds the reliability index targeted by the specification [16].

\section{Shear strain hardening in block shear failures}

The results of Equation (3) shown in Tables 2 and 3 indicate that full shear strain hardening was generally achieved by the specimens tested by Orbison et al. [10] and Gross et al. [11], as would be rationally expected since the applied loads were resisted by the "block" in shear only due to 
either the removal or the complete fracture of the tensile resistance planes, as illustrated in Figure 3. The ultimate shear load of such a specimen could only be reached after the shear strain hardening reserve was exhausted, although bolt hole deformations could cause a shift of the critical shear planes.

Interestingly, Teh \& Yazici [14] have found that full shear strain hardening was apparently achieved at the limit state of block shear failures of bolted connections in hot-rolled steel plates, where the mechanism was shear yielding and tensile rupture. The fact that the shear stresses of the angle specimens tested by Gross et al. [11] had reached complete strain hardening at the ultimate limit state of block shear failure (just before the net tensile section ruptured) can be concluded from their observation "In each test, the applied load decreased immediately upon rupture of the tension plane. In all specimens except A588-8, A588-9 and A588-10, the load then remained relatively constant as elongation continued until in-plane bending caused a further, gradual load reduction. With the tension plane ruptured, this constant load was resisted entirely by the shear plane." Had shear strain hardening been absent or insignificant at the ultimate limit state of block shear failure (just before the net tensile section ruptured), the shear load would have increased considerably with the strain hardening potential evident from the ratios of tensile strength to yield stress $F_{\mathrm{u}} / F_{\mathrm{y}}$ shown in Table 3.

Teh \& Yazici [14] found that full or almost full shear strain hardening at the limit state of block shear failure was true for a very wide range of bolted connections in flat plates tested by researchers around the world, which had bolt rows ranging from two to eight. In the seminal work of Hardash \& Bjorhovde [19], it had previously been found that the use of the ultimate shear stress instead of the yield shear stress in predicting the block shear capacities was more accurate for short connections, while the reverse was true for long connections. This apparent 
indication was caused by the use of the gross shear areas in computing the shear resistance component. As the number of bolt rows increases, the excess of the gross shear area $A_{\mathrm{gv}}$ over the active shear area $A_{\mathrm{av}}$ becomes larger, necessitating the use of the yield stress $F_{\mathrm{y}}$ rather than the (correct) ultimate stress $F_{\mathrm{u}}$ in order to compensate for the excess.

The contrast between the finding of Teh \& Yazici [14] and that of Teh \& Clements [1], who found minimal shear strain hardening among bolted connections in cold-reduced steel sheets, is most likely due to the much greater ductility of hot-rolled steel plates.

\section{Block shear failure loads of hot-rolled steel tee sections}

Based on the verification and exposition in the preceding sections, the block shear resistance of a bolted connection in hot-rolled steel plates should be computed from

$$
R_{n}=F_{u} A_{n t}+0.6 F_{u} A_{a v}
$$

in which $A_{\mathrm{nt}}$ is the net tensile area depicted in Figure 2 for a "symmetric" connection. It should be noted that the material tensile strength $F_{\mathrm{u}}$ in the shear resistance term of Equation (4) does not provide for shear "rupture" as in the AISC equations shown in Table 1, but for full strain hardening during shear yielding.

Equation (4) has been demonstrated by Teh \& Yazici [14] to be significantly more accurate than alternative equations including the AISC equations shown in Table 1, for bolted connections in flat gusset plates. In the present work, Equation (4) is verified against the block shear failure loads of tee sections bolted at the web and tested by Orbison et al. [10], a specimen of which is shown in Figure 4. The variable $A_{\mathrm{nt}}$ in this case denotes the tensile area that can be seen to have 
fractured in the photograph. All the specimens were subjected to load eccentricities, as illustrated in Figure 5, which means that, relative to the active shear planes, the net tensile planes reached the critical stress even earlier than those in concentrically loaded flat gusset plates.

However, it can be seen from Table 4 that, even in such cases, Equation (4) provides reasonably accurate estimates of the block shear failure loads. In contrast, the latest AISC's block shear provision [16], represented by the last equation in Table 1, leads to significant underestimations for most specimens, up to about $25 \%$. These outcomes are despite the fact that the specimens were loaded eccentrically, owing to the ductility of the steel material that had a yield stress of $335 \mathrm{MPa}$ and a tensile strength of $463 \mathrm{MPa}$.

In any case, the results of Equation (4) shown in Table 4 demonstrate that full shear strain hardening is generally achieved in the block shear failure of a hot-rolled steel bolted connection, reinforcing the finding discussed in the preceding section.

Teh \& Yazici [14] have calculated that, for Equation (4) to be applied to the design of gusset plates, a resistance factor of 0.85 is recommended in order to achieve a reliability index of 4.0 targeted by the specification [16].

\section{Conclusions}

Verifications of the active shear planes of bolted connections, previously identified by the first author for determining the block shear capacity, against independent and direct experimental results have been presented in this paper. It has been demonstrated that the critical shear planes are best represented by the active shear planes rather than either the gross or the net shear planes. Errors associated with the use of the gross or net shear planes can be considerable. 
It has been pointed out that full or almost full shear strain hardening is generally achieved at the ultimate limit state of block shear failure of bolted connections in hot-rolled steel plates or sections, irrespective of the connection length. The apparent lack of shear strain hardening in long connections observed by some researchers is due to the use of the gross shear area in computing the shear resistance component, the excess of which over the active shear area is compensated by neglecting the shear strain hardening.

The use of the active shear planes in conjunction with full shear strain hardening was shown to lead to reasonably accurate estimates even for eccentrically loaded tee sections bolted at the web. In contrast, it has been demonstrated that the current AISC's block shear provision is unnecessarily conservative for hot-rolled steel bolted connections.

For the block shear equation proposed in the present work to be applied to the design of gusset plates, a resistance factor of 0.85 is recommended in order to achieve a reliability index of 4.0 targeted by the AISC specification for structural steel buildings.

\section{References}

[1] Teh LH, Clements DDA. Block shear capacity of bolted connections in cold-reduced steel sheets. J Struct Eng 2012; 138 (4): 459-467.

[2] AISC. Specification for the Design, Fabrication and Erection of Structural Steel for Buildings, American Institute of Steel Construction, 1978.

[3] AISC. Load and Resistance Factor Design Specification for Structural Steel Buildings, American Institute of Steel Construction, 1986. 
[4] AISC. Allowable Stress Design Specification for Structural Steel Buildings, American Institute of Steel Construction, 1989.

[5] AISC. Load and Resistance Factor Design Specification for Structural Steel Buildings, American Institute of Steel Construction, 1993.

[6] AISC. Load and Resistance Factor Design Specification for Structural Steel Buildings, American Institute of Steel Construction, 1999.

[7] ANSI/AISC 360-05. Specification for structural steel buildings, American Institute of Steel Construction, 2005.

[8] Birkemoe PC, Gilmor MI. Behavior of bearing-critical double-angle beam connections. Eng J AISC 1978; 15 (4): 109-115.

[9] Clements DDA, Teh LH. Active shear planes of bolted connections failing in block shear. J Struct Eng 2013; 139 (3): 320-327.

[10] Orbison JG, Wagner ME, Fritz WP. Tension plane behavior in single-row bolted connections subject to block shear. J Construct Steel Res 1999; 49: 225-239.

[11] Gross JM, Orbison JG, Ziemian RD. Block shear tests in high-strength steel angles. Eng J AISC 1995; 32 (3) : 117-122.

[12] Rosenstrauch PL, Sanayei M, Brenner BR. Capacity analysis of gusset plate connections using Whitmore, block shear, global section shear, and finite element models. Eng Struct 2013; 48: 543-557.

[13] Fang C, Lam ACC, Yam MCH, Seak KS. Block shear strength of coped beams with singlesided bolted connection. J Construct Steel Res 2013: 86: 153-166. 
[14] Teh LH, Yazici V. Block shear capacity of bolted connections in hot-rolled steel plates. Connection Workshop VII, European Convention for Constructional Steelwork Task Committee 10, 2013: 91-100.

[15] Teh LH, Yazici V. Unconventional block shear failures of bolted connections in coldreduced steel sheet. Eng Struct 2013; 56: 567-571.

[16] ANSI/AISC 360-10. Specification for structural steel buildings, American Institute of Steel Construction, 2010.

[17] ECS. Eurocode 3: Design of steel structures, Part 1.8: Design of joints, EN 1993-1-8, European Committee for Standardisation, 2005.

[18] Aalberg A, Larsen PK. Strength and ductility of bolted connections in normal and high strength steels, Report N-7034, Dept. of Structural Engineering, Norwegian University of Science and Technology, Trondheim, Norway, 1999.

[19] Hardash SG, Bjorhovde R. New design criteria for gusset plates in tension. Eng J AISC 1985; 22 (2): 77-94. 


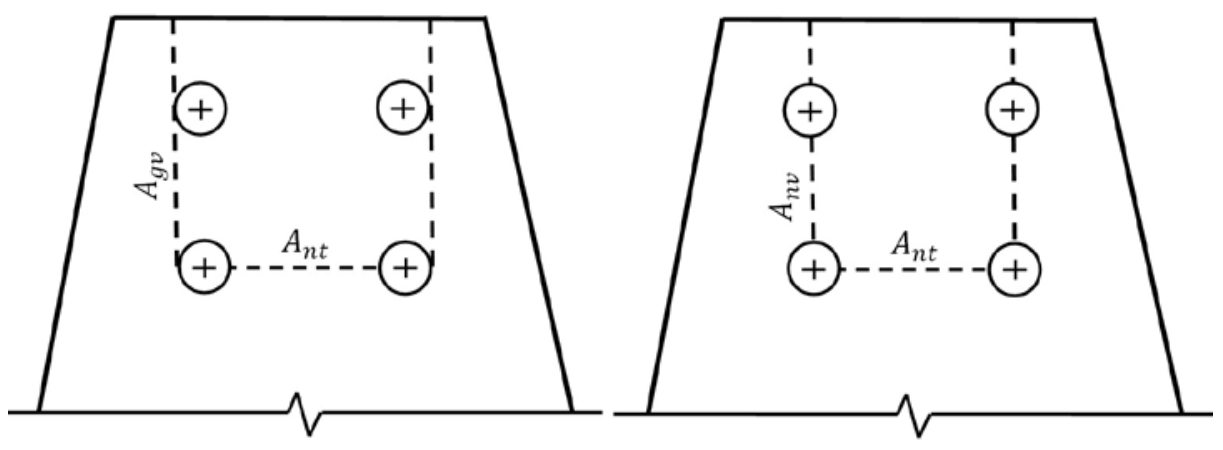

(a)

(b)

Figure 1 Nominal shear planes: (a) gross; (b) net 


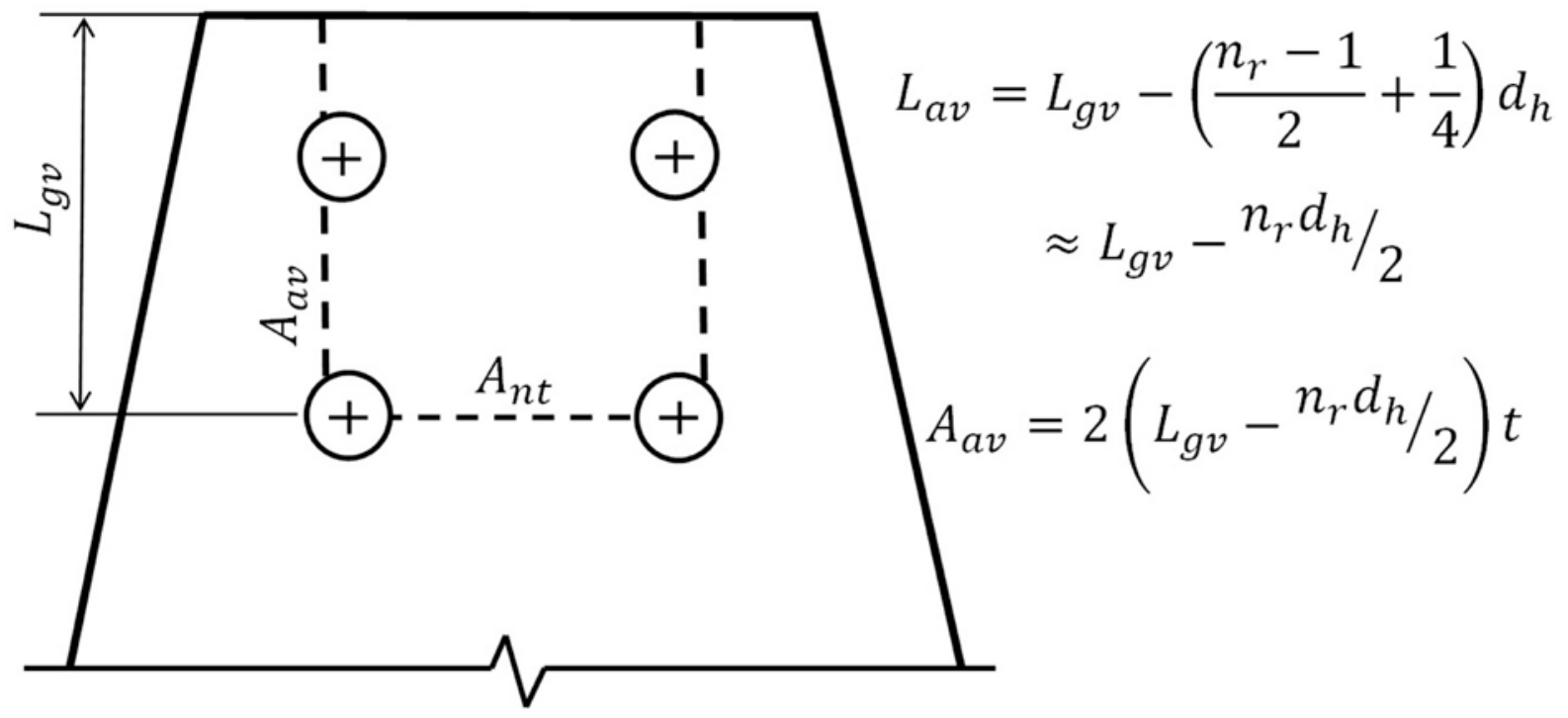

Figure 2 Active shear planes 


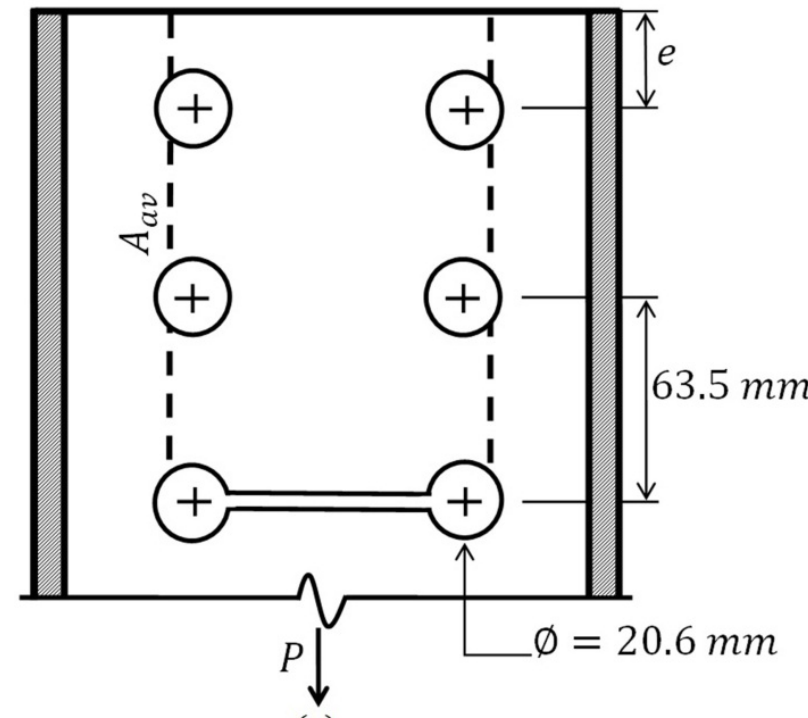

(a)

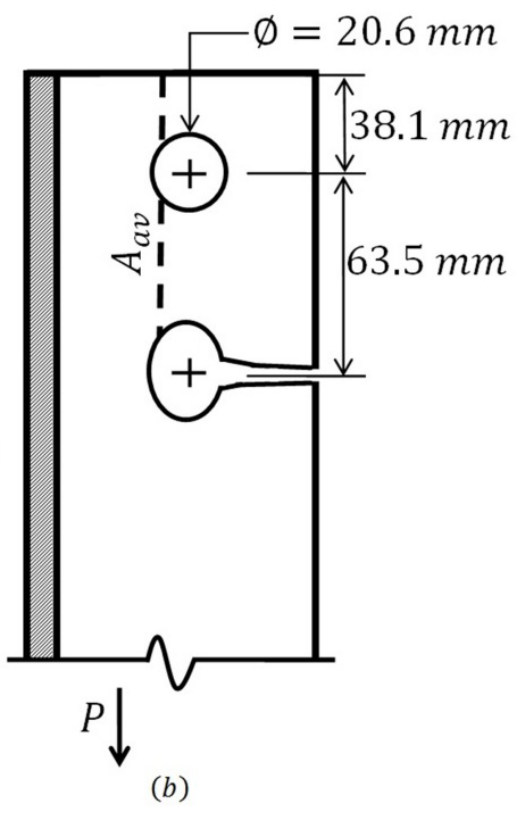

Figure 3 Shear resistance specimens: (a) sawn-off wide flange section [10]; (b) fractured angle [11] 


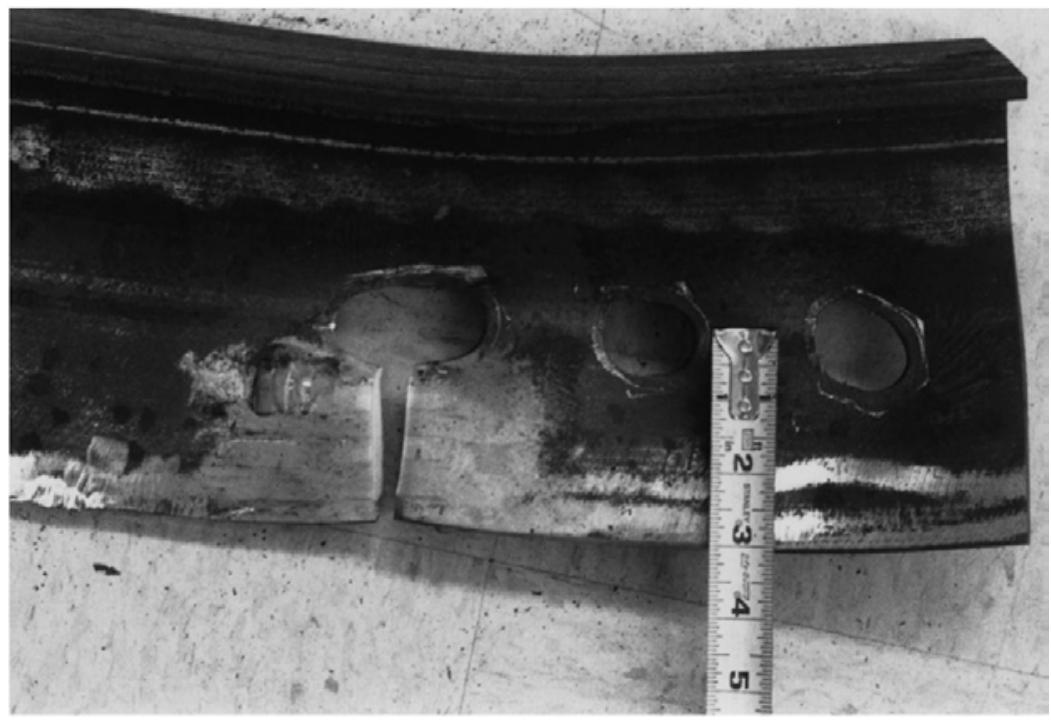

Figure 4 Tee section bolted at the web failing in block shear [10] 


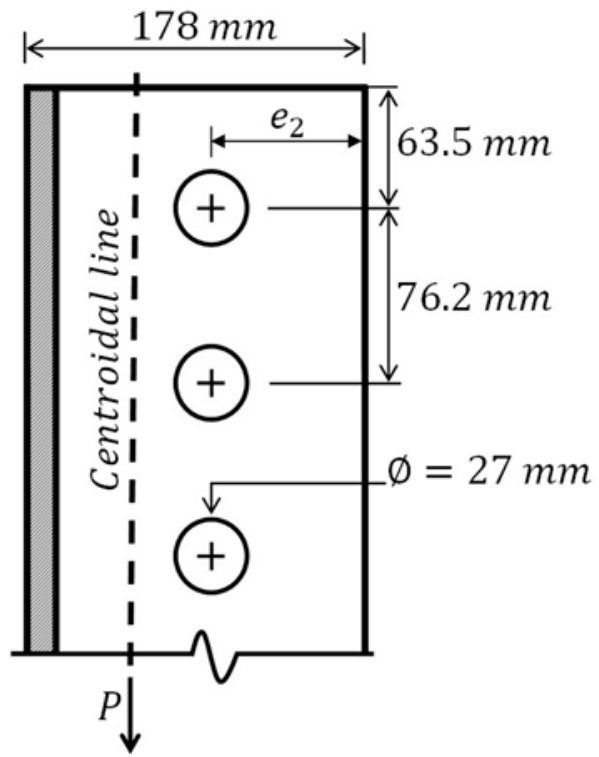

Figure 5 Tee section bolted at the web [10] 